\title{
Street food and nutrition security
}

Beuy Joob ${ }^{1}$

Viroj Wiwanitkit ${ }^{2}$

${ }^{1}$ Sanitation 1 Medical Academic Center, Bangkok

Thailand

${ }^{2}$ University of Nis, Serbia

Sir, the recent report on street food and nutrition security is very interesting ${ }^{1}$. Bezerra et al. ${ }^{1}$ concluded that "it is essential to improve the quantity and quality of the training of food handlers in order to implement food and nutrition security as promoting the human right to adequate food". In fact, street food can be seen worldwide and street food shop is a common place for eating for people living in several developing countries. It is no doubt that if there is no good sanitation, street food can be the source of infectious disease outbreak. According to a recent report by Piyaphanee et al. on traveler's diarrhea in Thailand, "food from streetvendors" is the main food source ${ }^{2}$. However, it should be noted that some travelers got the problem from food from restaurant. Hence, it is suggested that food sanitation must be applied for all food sellers, not only in street foot shop but also in luxury restaurant.

\section{References}

1. Bezerra AC, Mancuso AM, Heitz SJ. Street food in the national agenda of food and nutrition security: an essay for sanitary qualification in Brazil. Cien Saude Colet 2014; 19(5):1489-1494.

2. Piyaphanee W, Kusolsuk T, Kittitrakul C, Suttithum W, Ponam T, Wilairatana P. Incidence and impact of travelers' diarrhea among foreign backpackers in Southeast Asia: a result from Khao San road, Bangkok. J Travel Med 2011; 18(2):109-114. 